\title{
Trichotillomania: the impact of treatment history on the outcome of an Internet-based intervention
}

\author{
This article was published in the following Dove Press journal: \\ Neuropsychiatric Disease and Treatment \\ 21 April 2017 \\ Number of times this article has been viewed
}

\author{
Steffi Weidt ${ }^{1}$ \\ Annette Beatrix Bruehl 2,3 \\ Aba Delsignore' \\ Gwyneth Zaii,4-6 \\ Alexa Kuenburg' \\ Richard Klaghofer' \\ Michael Rufer' \\ 'Department of Psychiatry and \\ Psychotherapy, University Hospital \\ Zurich, University of Zurich, \\ Zurich, Switzerland; ${ }^{2}$ Department \\ of Psychiatry, Behavioural and \\ Clinical Neuroscience Institute, \\ University of Cambridge, Cambridge, \\ UK; ${ }^{3}$ Department of Psychiatry, \\ Psychotherapy and Psychosomatics, \\ University Hospital of Psychiatry, \\ Zurich, Switzerland; ${ }^{4}$ Department \\ of Psychiatry, Institute of Medical \\ Science, University of Toronto, \\ ${ }^{5}$ Neurogenetics Section, Centre \\ for Addiction and Mental Health, \\ ${ }^{6}$ Department of Psychiatry, Frederick \\ W. Thompson Anxiety Disorders \\ Centre, Sunnybrook Health Sciences \\ Centre, Toronto, ON, Canada
}

Correspondence: Steffi Weidt Department of Psychiatry and Psychotherapy, University Hospital Zurich, University of Zurich,

Culmannstrasse 8, CH-809I

Zurich, Switzerland

Tel +4I 442555280

Fax +4I 442554408

Email steffi.weidt@usz.ch
Background: Many patients suffering from trichotillomania (TTM) have never undergone treatment. Without treatment, TTM often presents with a chronic course. Characteristics of TTM individuals who have never been treated (untreated) remain largely unknown. Whether treatment history impacts Internet-based interventions has not yet been investigated. We aimed to answer whether Internet-based interventions can reach untreated individuals and whether treatment history is associated with certain characteristics and impacts on the outcome of an Internet-based intervention.

Methods: We provided Internet-based interventions. Subjects were characterized at three time points using the Massachusetts General Hospital Hairpulling Scale, Hamilton Depression Rating Scale, and the World Health Organization Quality of Life questionnaire.

Results: Of 105 individuals, 34 were untreated. Health-related quality of life (HRQoL) was markedly impaired in untreated and treated individuals. Symptom severity did not differ between untreated and treated individuals. Nontreatment was associated with fewer depressive symptoms $(P=0.002)$. Treatment history demonstrated no impact on the outcome of Internetbased interventions.

Conclusion: Results demonstrate that Internet-based interventions can reach untreated TTM individuals. They show that untreated individuals benefit as much as treated individuals from such interventions. Future Internet-based interventions should focus on how to best reach/ support untreated individuals with TTM. Additionally, future studies may examine whether Internet-based interventions can reach and help untreated individuals suffering from other psychiatric disorders.

Keywords: trichotillomania, health-related quality of life, treatment experience, Internet, online, hairpulling

\section{Introduction}

Approximately $1 \%-2 \%$ of the general population are affected by trichotillomania (TTM). ${ }^{1}$ TTM is characterized by repetitive hairpulling (criterion A, Diagnostic and Statistical Manual of Mental Disorders, Fifth Edition [DSM 5 $\left.]^{2}\right)$. TTM is associated with significant distress and functional impairment (criterion C, DSM 5), and patients' attempts of reducing hairpulling are usually unsuccessful (criterion $\mathrm{B}$, DSM 5). Most frequent locations of hairpulling are the scalp, eyebrows, and eyelashes. ${ }^{3}$ Affected individuals tend to avoid group activities because they are worried about their appearance and that others may uncover their problem. ${ }^{4,5}$ Approximately $86 \%$ of TTM individuals report a reduced quality of close friendships. ${ }^{6}$ Additionally, TTM often interferes with work performance and health-related quality of life (HRQoL), ${ }^{3,7}$ and it is frequently comorbid with other psychiatric disorders such as anxiety, mood, eating, ${ }^{8,9}$ and personality disorders. ${ }^{10}$ 
Cognitive-behavioral therapy (CBT), including habit reversal training (HRT), ${ }^{11}$ progressive muscle relaxation (PMR), ${ }^{12}$ acceptance and commitment therapy (ACT), ${ }^{13}$ and decoupling (DC), ${ }^{14,15}$ are effective treatments for TTM. However, individuals with TTM often report feelings of embarrassment and shame that have been shown to be significant barriers for them to access and seek treatment. ${ }^{3,7,8,16}$ Therefore, in adult individuals with TTM, the estimated prevalence of treatment is only $\sim 50 \%$. $^{3}$ Treatment often begins $\sim 9$ years after the onset of hairpulling. ${ }^{17}$ In addition to embarrassment and shamefulness, further possible reasons for nontreatment may include failure to recognize symptoms as a treatable problem and not knowing where to seek professional help. ${ }^{18}$ Without proper treatment, TTM almost always leads to a chronic and often debilitating course. ${ }^{19}$

Very few studies have investigated individual or illnessspecific characteristics, differentiating between individuals with and without previous treatment. In patients with obsessive compulsive disorder, studies have found no significant associations between gender and treatment history. ${ }^{20-22}$ Results on age and treatment history in obsessive compulsive disorder studies have been inconsistent. ${ }^{23-25}$

Whether individual characteristics (eg, age), illness characteristics (eg, severity of hairpulling), and/or impairment of HRQoL are associated with treatment history of TTM individuals is not yet known. Thus, learning more about the similarities and differences in the characteristics of treated and untreated TTM individuals may guide researchers and clinicians to find individualized approaches to access and support those who have never been treated or identified through the conventional therapeutic network. One approach to support untreated individuals may be via Internet/mobile-based interventions. ${ }^{26,27}$ However, whether such interventions can access and benefit untreated individuals compared to previously treated individuals has never yet been investigated. Thus, the present study has mainly focused on the following hypotheses:

- Untreated individuals with TTM can be accessed via Internet-based interventions.

- Individual (eg, age) and specific TTM characteristics (eg, severity of symptoms) do not differ between untreated and treated individuals, but more severe depressive symptoms, as in the case of OCD individuals, are associated with previous treatment.

- Previously untreated individuals benefit from the provided Internet-based interventions and do not have a higher dropout rate than previously treated individuals.

\section{Methods}

Our TTM sample was recruited from an Internet-based interventional, double-blind randomized controlled trial (NCT02044237), which was published previously. ${ }^{15}$ The study was approved by the local ethics committee of the Canton of Zurich in Switzerland and was conducted according to the Declaration of Helsinki. All participants gave their written (electronic) informed consent.

\section{Participants}

A total of 141 individuals signed the electronic informed consent form. The inclusion criteria were adult individuals who met the diagnostic criteria for TTM according to $D S M-I V$-TR. ${ }^{28}$ Exclusion criteria were current suicidal ideations, dependency of alcohol or drugs, and/or current psychotic episodes. Other comorbid AXIS I disorders were assessed but were not considered as exclusion criteria due to the known high rate of psychiatric comorbidity in TTM. Individuals were excluded if they discontinued the pretreatment assessment $(\mathrm{n}=20)$. An additional 16 individuals were excluded because they were interested in the study but did not meet criteria for TTM $(n=4)$, they could not be contacted for the telephone interview $(n=6)$, they decided not to take part in the interview $(n=1)$, and they met the exclusion criteria (four individuals with current suicidal ideations, one with current alcohol dependency; flow chart, Figure 1).

With regard to treatment history, individuals were asked if they have ever received professional help (such as psychiatric, psychotherapeutic, and/or psychopharmacological treatment) and/or if they were currently treated for any mental health problem. This assessment did not refer to the specific and targeted treatment for TTM since we aimed to also include additional TTM-related mental health problems (such as depressive symptoms) in the study. Individuals who answered "no" for both questions were assigned to the "never-treated/untreated" group ( $\mathrm{N}=34)$. If one or both questions were answered affirmatively, individuals were assigned to the "previously treated/treated" group ( $\mathrm{N}=71)$.

\section{Procedures}

A web link directed potential participants to the pretreatment assessment (UNIPARK, QuestBack ${ }^{\mathrm{TM}}$ ). After the pretreatment assessment, individuals were contacted for a telephone interview in order to assess for the diagnostic criteria of TTM, depressive symptoms, and psychiatric comorbidity. Participants were then randomly allocated to one of two intervention 


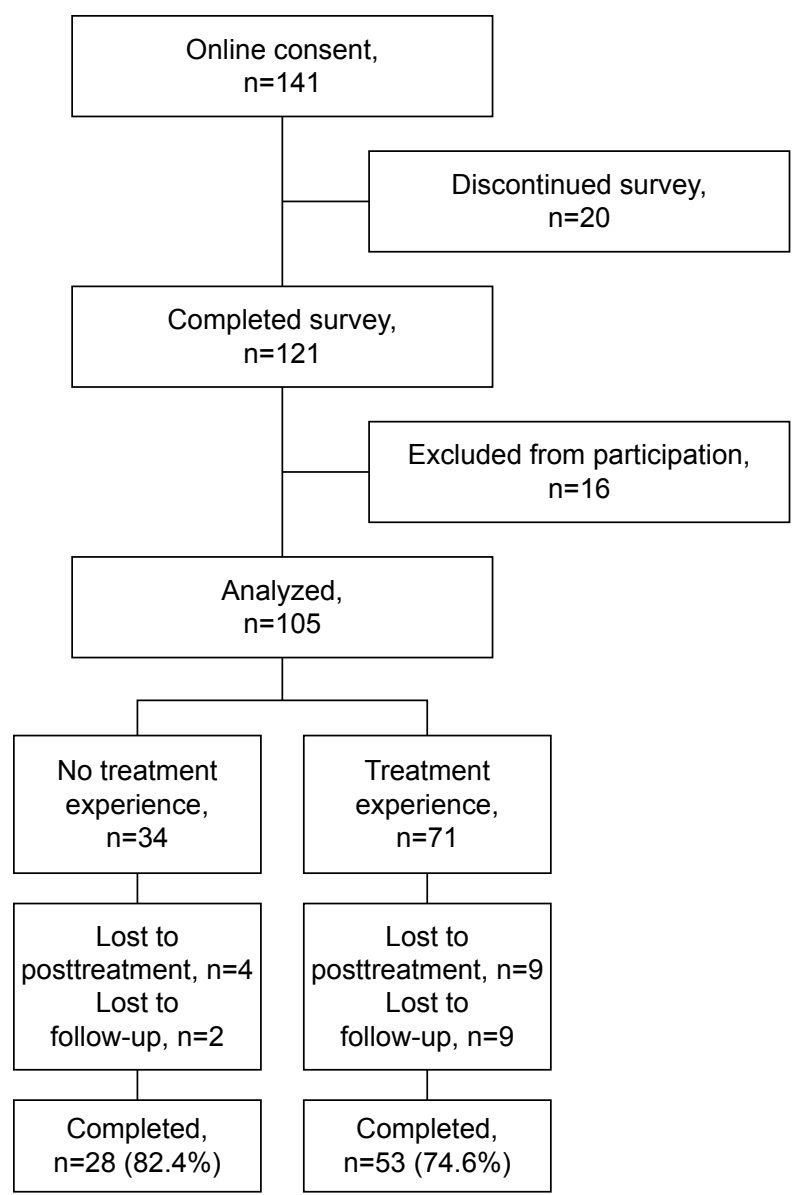

Figure I Consort diagram of never-treated and previously treated subjects from baseline to follow-up.

groups (decoupling or PMR). ${ }^{15}$ After the 4-week intervention period and the 6-month follow-up, subjects completed questionnaires and were interviewed by phone.

\section{Interventions}

Detailed information is given in the study of Weidt et al. ${ }^{15}$ In short, both methods (decoupling and PMR) were mailed to the participants in PDF files, which included written and illustrated instructions. Decoupling instructed the participants to redirect their movement from the hair to a different target close to the pulling side or into the room (= decouple). ${ }^{14} \mathrm{PMR}$ followed standard instructions. ${ }^{29}$ During the online self-help intervention participants in both groups received weekly identically worded email support.

\section{Measures}

The Massachusetts General Hospital Hairpulling Scale (MGH-HPS, German version) was administered to capture the severity of hairpulling..$^{30,31}$ The total score is the sum of seven self-report items (range: 0-28, higher scores indicating worse pulling). The instrument's internal consistency (0.89) and retest reliability $(\mathrm{r}=0.97)$ are excellent. ${ }^{30,32}$

The World Health Organization Quality of Life questionnaire (WHOQOL-BREF, German version) was used to assess HRQoL. ${ }^{33,34}$ The scale contains 26 items that are coded on a five-point scale. The items can be summarized in four composite scores (WHO-physical, WHO-psychological, WHO-social relationships, and WHO-environment) and one global score (WHO-global) with higher scores indicating better HRQoL. Reference values of the German general population are available. ${ }^{34}$

To assess general psychopathology, a short form (SCLK-9, German version $)^{35}$ of the Symptom Checklist SCL-90- $R^{36}$ was applied. The SCL-K-9 results in the Global Severity Index (GSI). The GSI represents the mean score of nine items (range $0-4$, higher scores indicating more severe general psychopathology).

Comorbid psychiatric disorders were assessed with the Mini-International Neuropsychiatric Interview (M.I.N.I., German version). ${ }^{37,38}$

For clinician-rated depressive symptoms, the Hamilton Depression Rating Scale (HDRS-17, 17-item German version) was used. ${ }^{39,40}$ Ratings were determined during semistructured telephone interviews. The sum-score ranges between 0 and 52 (higher scores indicating worse symptoms).

All interviewers were clinically experienced psychologists/ psychiatrists and trained in the administration of M.I.N.I. and HDRS-17.

Sociodemographic and clinical data were obtained through structured questions regarding treatment experience, duration of illness, age, gender, and education.

\section{Analysis}

Group differences (untreated vs previously treated) at baseline were calculated using the Student's $t$-test for continuous variables and Pearson $\chi^{2}$ test for nominal variables (eg, pulling site). WHOQOL-bref scores of the two groups were compared between untreated and treated TTM individuals in addition to the German general population ${ }^{34}$ using the Student's $t$-test. To test whether treatment history potentially affects the outcome of Internet-based intervention, an intention-totreat analysis (ITT) with first observations carried forward (FOCF) and a completer's analysis were conducted. In both analyses, a general linear model with repeated measures (GLM-RM) and repeated contrasts was conducted for the dependent variables (MGH-HPS, HDRS-17, WHOQOL-bref 
subscores [not WHO environment], and SCL-K-9). Group (treatment history: untreated vs previously treated) served as the between-subject variable, and time (pre, post, follow-up) as the within-subject factor. A significant impact of treatment history can be seen in a significant interaction between group and time. Variables (baseline HDRS-17 and baseline WHOglobal) that had demonstrated baseline differences between both groups (untreated/previously treated) were included as covariates into the analyses, also the variable intervention group (decoupling/PMR). Assumptions for all analyses with GLM-RM were checked in terms of Box's test of equality of covariance matrices, Mauchly's test of sphericity, and Levene's test of equality of error variances. All assumptions were met, with the exception of a significant Box's test for the HDRS-17 and a significant Mauchly's test for the GSI (ITT and completers' analysis), which was considered with a Greenhouse-Geisser correction. Effect sizes (partial $\eta^{2}$ ) were calculated ( $\geq 0.01$ small effect, $\geq 0.06$ medium effect, and $\geq 0.14$ large effect size). ${ }^{41}$

All statistical calculations were performed using the software package SPSS (Version 22.0). The level of significance was set at $P<0.05$ (two-sided).

\section{Results}

Baseline characteristics of individuals without previous treatment compared to those with previous treatment

Table 1 presents the results of the comparisons between untreated $(n=34,32.4 \%)$ and previously treated individuals $(n=71,67.6 \%)$. Individuals in the untreated group were significantly less likely to pull hair from their own scalp and showed lower HDRS-17 scores and higher global HRQoL (WHO-global). They did not differ in duration of symptoms and severity of hairpulling.

\section{Baseline HRQoL of the two groups and compared to the German population}

Figure 2 depicts the mean scores on the WHOQOL-bref subscales for both groups separately and compared to the German population (age matched, range 18-65 years). In both groups (untreated and previously treated), the mean scores on the subscales physical, psychological, and social relationships of the WHOQOL-bref were significantly lower than those of the general population. Environmental HRQoL

Table I Characteristics and illness symptoms of previously treated subjects with TTM (T) and untreated subjects with TTM (NT) at baseline

\begin{tabular}{|c|c|c|c|c|c|}
\hline Variable & NT $(n=34)$ & $T(n=7 I)$ & Test statistics & $d f$ & $P$-value \\
\hline Gender: male & $\mathrm{N}=4(\mathrm{II} .8 \%)$ & $\mathrm{N}=\mathrm{I}(\mathrm{I} .4 \%)$ & c & - & - \\
\hline Age, years & 31.35 & 32.42 & -0.52 & 103 & $0.60^{\mathrm{b}}$ \\
\hline Age at onset, years & 13.65 & 13.73 & -0.06 & 103 & $0.96^{\mathrm{b}}$ \\
\hline Diagnostic delay, years & 9.74 & 9.90 & -0.10 & 103 & $0.93^{b}$ \\
\hline DoS, years & |8.7| & 19.69 & -0.46 & 103 & $0.65^{b}$ \\
\hline Comorbid disorders - yes & $\mathrm{N}=15(44.1 \%)$ & $\mathrm{N}=40(56.3 \%)$ & 1.34 & 1 & $0.24^{a}$ \\
\hline Higher education & $\mathrm{N}=28(82.4 \%)$ & $\mathrm{N}=50$ (70.4\%) & 1.79 & I & $0.18^{a}$ \\
\hline Employed & $\mathrm{N}=17(50 \%)$ & $\mathrm{N}=32$ (45.1\%) & 0.22 & $\mathrm{I}$ & $0.64^{a}$ \\
\hline MGH-HPS & 17.12 & 18.27 & -1.11 & 103 & $0.27^{b}$ \\
\hline Number of pulling sites & 1.53 & 1.83 & -1.36 & 103 & $0.18^{b}$ \\
\hline Pulling site - scalp & $\mathrm{N}=22(64.7 \%)$ & $\mathrm{N}=62(87.3 \%)$ & 6.95 & 1 & $0.008^{\mathrm{a}}$ \\
\hline Pulling site - eyebrow & $\mathrm{N}=15(44.1 \%)$ & $\mathrm{N}=20(28.1 \%)$ & 2.58 & I & $0.1 \mathrm{I}^{\mathrm{a}}$ \\
\hline Pulling site - eyelashes & $\mathrm{N}=8(23.5 \%)$ & $\mathrm{N}=2 \mathrm{I}(29.6 \%)$ & 0.43 & I & $0.5 \mathrm{I}^{\mathrm{a}}$ \\
\hline Pulling site - not visible & $\mathrm{N}=6(17.6 \%)$ & $\mathrm{N}=18(25.4 \%)$ & 0.8 & 1 & $0.3 I^{a}$ \\
\hline GSI & 1.54 & 1.59 & -0.33 & 103 & 0.74 \\
\hline HDRS-I7 & 5.68 & 9.85 & -3.19 & 103 & $0.002^{\mathrm{b}}$ \\
\hline \multicolumn{6}{|l|}{ WHOQOL-bref subscale } \\
\hline Global & 64.34 & 54.58 & 2.28 & 103 & $0.024^{b}$ \\
\hline Physical & 73.32 & 68.85 & 1.70 & 103 & $0.09^{\mathrm{b}}$ \\
\hline Psychological & 56.37 & 49.59 & 1.72 & 103 & $0.09^{b}$ \\
\hline Social relationships & 56.13 & 52.11 & 0.89 & 103 & $0.38^{\mathrm{b}}$ \\
\hline Environment & 71.42 & 72.71 & $-0.4 \mathrm{I}$ & 103 & $0.68^{b}$ \\
\hline
\end{tabular}

Notes: Values are mean values unless specified otherwise. ${ }^{a} \chi^{2}$ test. ${ }^{b}$-test; significant $P$-values are shown in bold; ${ }^{c}$ not calculated due to very small numbers.

Abbreviations: TTM, trichotillomania; DoS, duration of symptoms; MGH-HPS, Massachusetts General Hospital Hairpulling Scale; GSI, Global Severity Index; HDRS-I7, Hamilton Depression Rating Scale, 17-item version; WHO, World Health Organization; WHOQOL-bref, WHO Quality of Life questionnaire short form. 


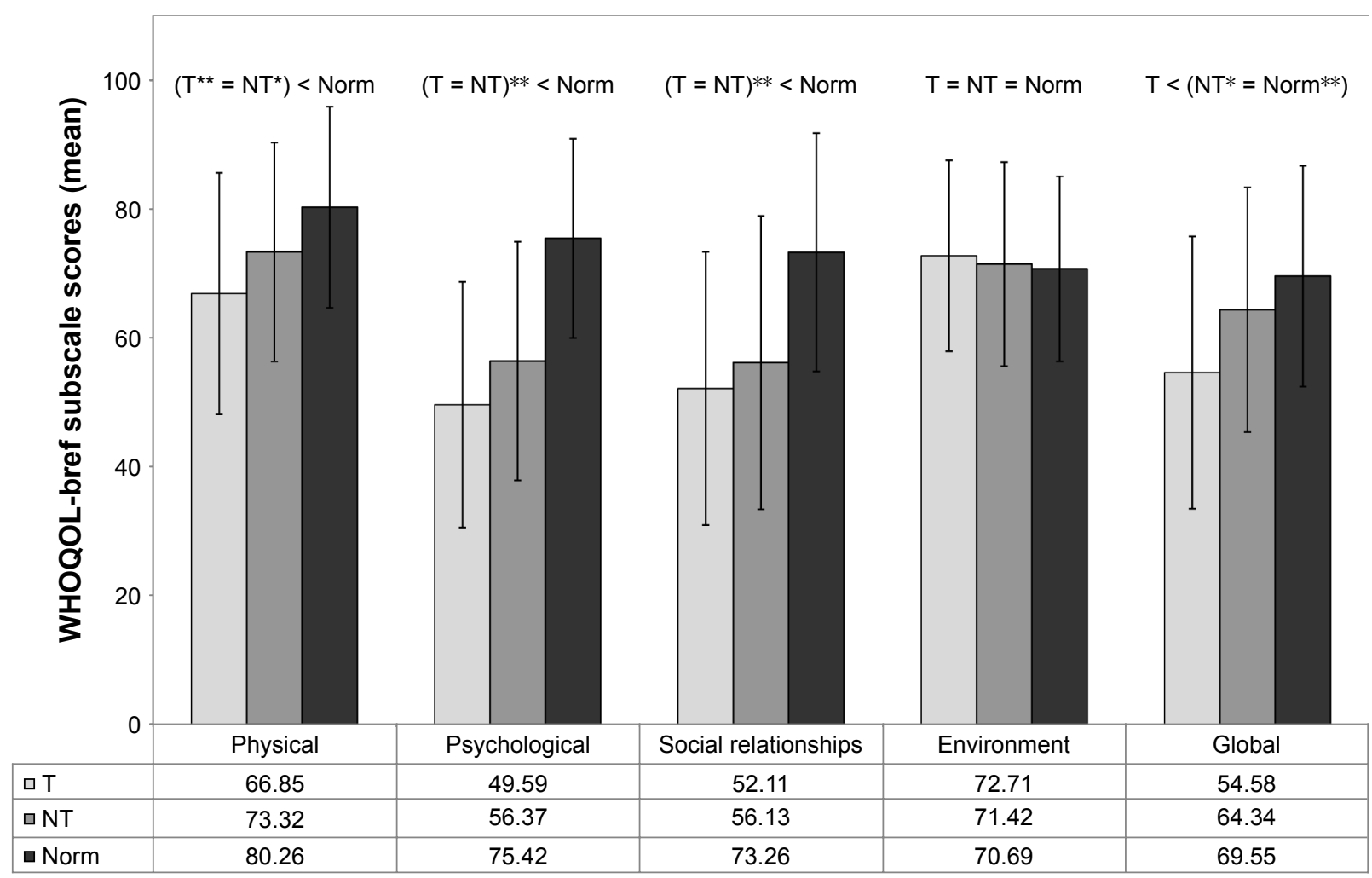

Figure 2 Health-related quality of life of previously treated TTM subjects (T) vs never treated TTM subjects (NT) and in comparison with the general German population (Norm). Notes: $* * P<0.001, * P<0.05$, higher scores indicate better health-related quality of life.

Abbreviations: TTM, trichotillomania; WHO, World Health Organization; WHOQOL-bref, WHO Quality of Life questionnaire short form.

was similar to that of the general population for both groups. Global HRQoL was significantly impaired in the previously treated group but not in the untreated group. The comparison of the two groups demonstrated no significant differences in the WHOQOL-bref subscales, except for global HRQoL, which was lower in the treated group (Table 1 and Figure 2).

\section{Effect of treatment history on hairpulling severity, depressive symptoms, HRQoL, and global severity outcome ITT ( $\mathrm{N}=105)$}

Effects over time were significant for all dependent variables ( $P \leq 0.001$, except: WHO-social relationships, $P=0.06$; Table 2). We observed no significant effect for any of the group $\times$ time interactions ( $P$ from 0.08 to 0.72 ), indicating that treatment history did not affect the outcome of the Internet-based intervention. Group $\times$ time interaction did not change significantly after including the covariates 1) baseline HRDS-17, 2) baseline WHO-global, and 3) intervention group (decoupling/PMR) into the GLM of the ITT analyses (Table 2, $P$ from 0.053 to 0.71 ).

\section{Completer analysis $(\mathrm{N}=8 \mathrm{I})$}

Number of dropouts from baseline to follow-up did not differ between the two groups (untreated $=6 ; 17.6 \%$, previously treated $=18 ; 25.4 \%$; Pearson $\left.\chi^{2}=0.38\right)$. Completer analyses demonstrated significant effects over time for all dependent variables (Table $3, P$ from $\leq 0.05$ to $\leq 0.001$ ). We observed the same lack of significant group $\times$ time interactions as in the intention-to-treat analyses ( $P$ from 0.1 to 0.75 ). Including covariates (as mentioned earlier) did not change group $\times$ time interaction significantly (Table $3, P$ from 0.14 to 0.93 ).

\section{Discussion}

To the best of our knowledge, this is the first study comparing clinical characteristics between untreated and previously treated individuals suffering from TTM and examining the potential effect of treatment history on the outcome of an Internet-based intervention. Both untreated and previously treated individuals with TTM demonstrated marked impairment in HRQoL compared with the general population. TTM individuals who have never received any previous treatment had significantly lower depressive symptoms, in addition to having significantly more hairpulling from other body areas 

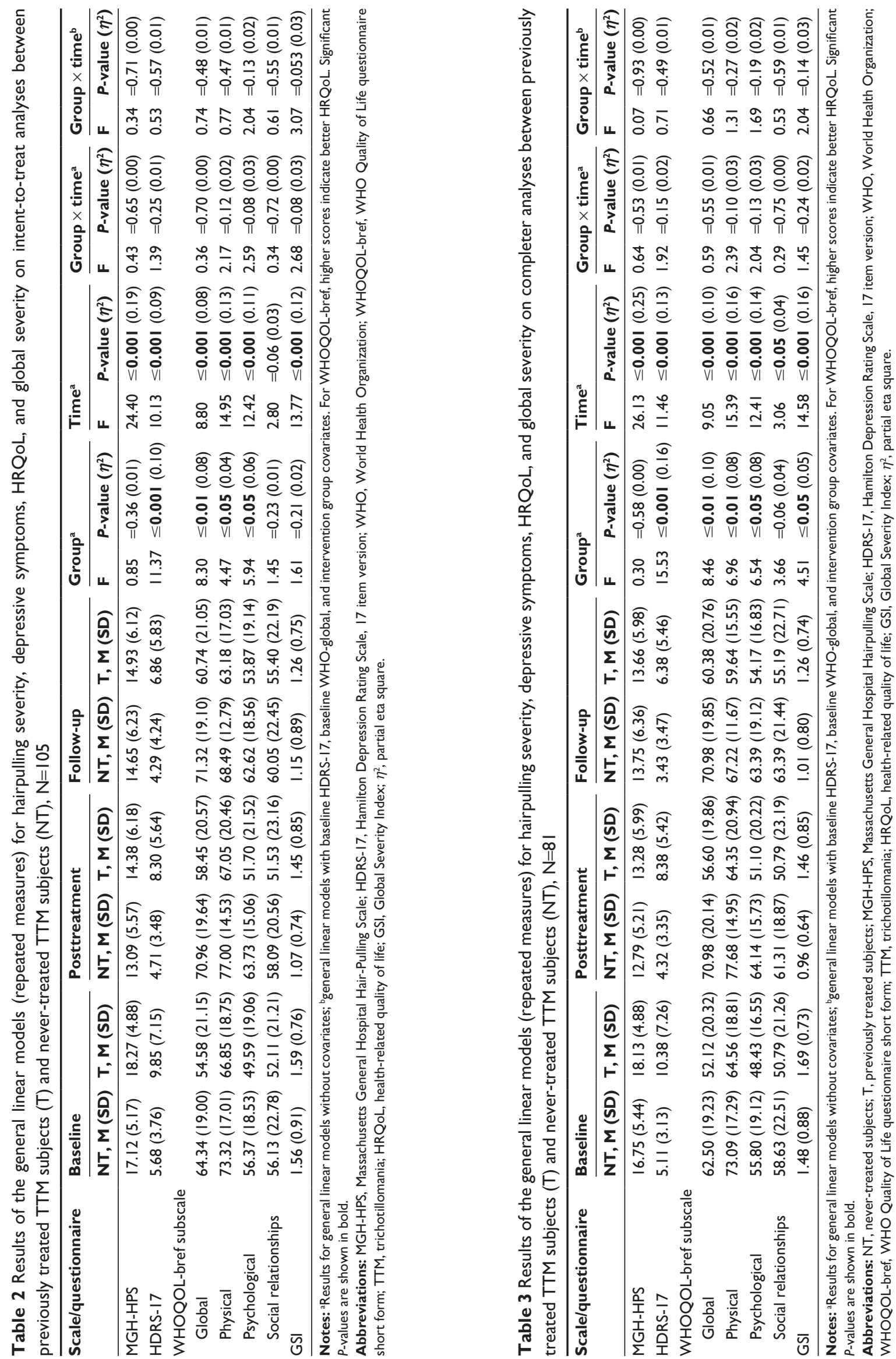
except from the scalp. Interestingly, treatment history did not affect the outcome of the Internet-based intervention and dropout rates did not differ between untreated and previously treated individuals.

Before a detailed discussion of the present study, we would like to acknowledge several limitations. One of the main limitations of our study is that the majority of individuals were female. Therefore, it would be imprudent to apply our current results to males. However, previous TTM online studies have reported similar female predominance in their study sample. ${ }^{3,16}$ Whether this reflects TTM as having a higher prevalence in females ${ }^{1,42}$ or females with greater information- or help-seeking behavior ${ }^{43}$ remains an important but yet unsolved question. ${ }^{11,44}$

Although $32.4 \%$ of participants of the current sample were untreated individuals, this number appears to be considerably lower than the number of individuals not receiving treatment in the community and in other published epidemiological studies $\left(\sim 50 \%\right.$, eg, the study of Woods et $\left.\mathrm{al}^{3}\right)$. One reason for this discrepancy might be due to the assessment history. We inquired about the general psychiatric treatment history and did not explicitly seek treatment history specific to TTM. We also did not ask the participants about their reasons for not receiving any treatment. For those who have received treatment, we also did not inquire whether their treatment was perceived as helpful. In addition, we cannot exclude recall bias by participants who might have had difficulties to accurately recall therapy experiences from the past.

To reduce potential interrater disagreement all three raters were trained and interviews followed clearly stated guidelines for M.I.N.I. and HDRS-17.

One of the strengths of the present study in contrast to many other online studies was the external validation of the diagnosis of TTM. Furthermore, we used a longitudinal study design in order to assess differences between individuals with and without previous treatment history and also to investigate whether these differences affect the outcome of an Internet-based intervention.

As the probability of treatment often correlates with disorder severity, ${ }^{45}$ a crucial step when interpreting findings in untreated individuals is to consider whether they have clinically relevant symptoms. If, for example, such individuals had only minor hairpulling symptoms and good HRQoL, this alone might explain their nontreatment. Overall, both patient groups reported longstanding symptoms and considerable impairment of HRQoL. Nevertheless, global HRQoL and depressive symptoms were less severe in untreated individuals compared to those who have previously sought treatment. While these results implied that certain untreated individuals might not have sought treatment before due to a relatively lower functional impairment, severity of hairpulling, duration of hairpulling symptoms, and global severity did not differ between the groups. Furthermore, there was no significant difference in the number of psychiatric comorbid disorders, and all participants were motivated enough to seek help in the current intervention study, indicating substantial amount of suffering in both groups of TTM participants (treated and untreated).

Three potential explanations can be discussed for the association of depressive symptoms and treatment history. 1) Because of the feeling of shamefulness ${ }^{5}$ and fear of negative reactions from others, ${ }^{20}$ the attempt to conceal hairpulling symptoms often delays treatment seeking in individuals with TTM. ${ }^{3,7}$ However, due to effective health education and global awareness on depressive symptoms over the last decade, the shame and stigma to disclose depressive symptoms have slowly reduced. ${ }^{46}$ Therefore, individuals may feel more comfortable to disclose depressive than hairpulling symptoms. 2) The association between nontreatment and relatively low depression scores is further supported by findings in other psychiatric patient populations. For instance, lower depression scores have been reported in patients with social phobia who sought treatment for the first time compared to those with prior treatment history. ${ }^{47}$ Among psychiatric patients, interference with daily living due to depressive symptoms is one of the major motivations for individuals to seek professional treatment..$^{20,23,48,49}$ 3) Physicians are often more familiar and knowledgeable to manage depressive symptoms ${ }^{50,51}$ than hairpulling symptoms, ${ }^{44,52}$ this in turn may allow individuals to disclose their depressive symptoms more willingly to their physicians. Thus, individuals with more severe depressive symptoms may be identified and provided treatment more often than those who have fewer depressive symptoms. Taken together, 1) feeling less shameful to disclose depressive symptoms than hairpulling symptoms, 2) the negative impact of depressive symptoms as a significant motivation for individuals to disclose their symptoms and seek help, and 3) the higher rate of identifying individuals with more severe depressive symptoms might explain the association between depressive symptoms and previous treatment history.

We demonstrated that individuals without a previous treatment history benefited to the same extent from the provided intervention compared to individuals with a prior treatment history. Additionally, dropout rates did not differ between the untreated and treated groups. These findings 
were encouraging because they suggested that Internet-based interventions may be effective in treating TTM individuals, independent of their treatment history.

In the following section, we would like to discuss possible reasons that may explain the present findings. 1) Even though TTM individuals with a previous treatment history might have benefited from their previous treatment, they did not report less hairpulling severity but instead reported more severe depressive symptoms at baseline than individuals without any prior treatment. Depressive symptoms have been shown consistently to be associated with cognitive impairments, ${ }^{53}$ and these symptoms could impair learning and the application of new adaptive behaviors. However, the severity level of depression in both samples was relatively low and did not reach diagnostic thresholds for a current depressive episode in most individuals. ${ }^{54}$ This might explain why potential cognitive effects of depression did not affect treatment outcome in this study. 2) While some studies reported that individuals with previous treatment are more likely to dropout from current therapies, ${ }^{55}$ the dropout rates did not differ between our studied groups. This finding is supported by the abovementioned study in patients suffering from social phobia ${ }^{47}$ - prior treatment was not associated with a change in dropout rates. A potential reason might be that prior treatment was less successful and/or less specific for TTM symptoms, and therefore, individuals attempting our new Internet-based intervention might be more motivated and desperate to complete the whole treatment program in order to learn new skills for reducing their TTM symptoms. 3) One might assume that individuals without previous treatment might, due to limited skills of reducing TTM symptoms compared with individuals with prior treatment, benefit to a lesser extent. However, previous treatment(s) might not be as comprehensive or successful, which might not have provided an additive improvement to our current Internet-based intervention(s). When interpreting our findings, it is important to keep in mind that the data were gathered and assessed via the Internet. Participants without previous treatment indeed sought help in our Internet-based intervention study. These individuals were actively searching for information and help related to TTM online; therefore, they might have at least some insights into their problems. Overall, the present study provided encouraging results and demonstrated that it is possible to access at least some of the "hidden" untreated individuals and that professional online information/ intervention might be important to successfully close the gap between being ill, having insight into symptoms and/or mental illness, seeking professional help, ${ }^{56}$ and benefiting from the provided Internet-based intervention(s).

\section{Conclusion}

Current results suggested that both TTM individuals with and without previous treatments suffer from clinically significant symptoms with substantial impairment in HRQoL. The severity of depressive symptoms was correlated with initiating treatment in TTM. Furthermore, the present study demonstrated that the Internet-based intervention reached out to certain "hidden" untreated TTM individuals, and TTM individuals benefited from such intervention independent of their treatment history. The dropout rates were comparable between the previously treated and untreated groups.

Future Internet-based interventions should especially be focused to reduce barriers for and to support "hidden" untreated TTM individuals in order to gain access to evidence-based online interventions that are tailored for them. The present study may be a stepping stone for future studies to examine whether "hidden" untreated individuals who suffer from different chronic and debilitating psychiatric disorders can be accessed online and can benefit from Internet-based interventions.

\section{Disclosure}

Potential conflicts of interest and support and financial involvement over the previous 3 years, regardless of their potential relevance to the paper are reported. The authors would like to acknowledge funding support from the Gottfried and Julia Bangerter-Rhyner Foundation and from the Novartis Foundation for medical-biological research. The authors advise that no granting or other outside parties had any role in the study's design or orchestration, including data collection and analysis, their decision to publish, or preparation of the manuscript. SW reports grants from Gottfried and Julia Bangerter-Rhyner Foundation, Novartis Foundation for medical-biological research, and University of Zurich - career development grant Filling the gap. ABB reports fellowship from the Swiss Foundation for Grants in Biology and Medicine (SFGBM) and the Swiss National Science Foundation (SNSF). AD reports grants from the University of Zurich Matching Fund and from the Johnson Foundation. GZ reports Canadian Institutes of Health Research (CIHR) Postdoctoral Fellowship and W Garfield Weston Doctoral Fellowship. AK reports no conflicts of interest in this work. MR reports speaker honoraria from AstraZeneca and Lundbeck Institute; research grants from 
the Gottfried and Julia Bangerter-Rhyner Foundation and the Novartis Foundation for medical-biological research. The authors report no other conflicts of interest in this work.

\section{References}

1. O'Sullivan RL, Keuthen NJ, Christenson GA, Mansueto CS, Stein DJ, Swedo SE. Trichotillomania: behavioral symptom or clinical syndrome? Am J Psychiatry. 1997;154(10):1442-1449.

2. APA. Dissociative Disorders. DSM-5. Vol. 1. Washington, DC, London: American Psychiatric Association; 2013:291-308.

3. Woods DW, Flessner CA, Franklin ME, et al. The Trichotillomania Impact Project (TIP): exploring phenomenology, functional impairment, and treatment utilization. J Clin Psychiatry. 2006;67(12): 1877-1888.

4. Diefenbach GJ, Tolin DF, Crocetto J, Maltby N, Hannan S. Assessment of trichotillomania: a psychometric evaluation of hair-pulling scales. J Psychopathol Behav. 2005;27(3):169-178.

5. Neudecker A, Rufer M. Behavior therapy of trichotillomania: review, behavioral analysis, and case history. Verhaltenstherapie. 2004;14(2): $90-98$.

6. Wetterneck CT, Woods DW, Norberg MM, Begotka AM. The social and economic impact of trichotillomania: results from two nonreferred samples. Behav Intervent. 2006;21(2):97-109.

7. Diefenbach GJ, Tolin DF, Hannan S, Crocetto J, Worhunsky P. Trichotillomania: impact on psychosocial functioning and quality of life. Behav Res Ther. 2005;43(7):869-884.

8. Cohen LJ, Stein DJ, Simeon D, et al. Clinical profile, comorbidity, and treatment history in 123 hair pullers: a survey study. J Clin Psychiatry. 1995; 56(7):319-326.

9. Christenson GA, Mackenzie TB, Mitchell JE. Characteristics of 60 adult chronic hair pullers. Am J Psychiatry. 1991;148(3):365-370.

10. Christenson GA, Chernoff-Clementz E, Clementz BA. Personality and clinical characteristics in patients with trichotillomania. J Clin Psychiatry. 1992;53(11):407-413.

11. Duke DC, Keeley ML, Geffken GR, Storch EA. Trichotillomania: a current review. Clin Psychol Rev. 2010;30(2):181-193.

12. Rothbaum BO. The behavioral treatment of trichotillomania. Behav Psychother. 1992;20(1):85-90.

13. Woods DW, Wetterneck CT, Flessner CA. A controlled evaluation of acceptance and commitment therapy plus habit reversal for trichotillomania. Behav Res Ther. 2006;44(5):639-656.

14. Moritz S, Rufer M. Movement decoupling: a self-help intervention for the treatment of trichotillomania. J Behav Ther Exp Psychiatry. 2011;42(1): 74-80.

15. Weidt S, Klaghofer R, Kuenburg A, et al. Internet-based self-help for trichotillomania: a randomized controlled study comparing decoupling and progressive muscle relaxation. Psychother Psychosom. 2015;84(6): 359-367.

16. Shusterman A, Feld L, Baer L, Keuthen N. Affective regulation in trichotillomania: evidence from a large-scale internet survey. Behav Res Ther. 2009;47(8):637-644.

17. Seedat S, Stein DJ. Psychosocial and economie implications of trichotillomania: a pilot study in a South African sample. CNS Spectr. 1998;3:40-43.

18. Rufer M, Moergeli H, Moritz S, Drabe N, Weidt S. Alexithymia and non-treatment: an Internet based study of 312 people with chronic anxiety. Compr Psychiatry. 2014;55(1):179-187.

19. Keuthen NJ, Fraim C, Deckersbach T, Dougherty DD, Baer L, Jenike MA. Longitudinal follow-up of naturalistic treatment outcome in patients with trichotillomania. J Clin Psychiatry. 2001;62(2):101-107.

20. Belloch A, Del Valle G, Morillo C, Carrio C, Cabedo E. To seek advice or not to seek advice about the problem: the help-seeking dilemma for obsessive-compulsive disorder. Soc Psychiatry Psychiatr Epidemiol. 2009;44(4):257-264.
21. Demet MM, Deveci A, Taskin EO, et al. Risk factors for delaying treatment seeking in obsessive-compulsive disorder. Compr Psychiatry. 2010;51(5):480-485.

22. Garcia-Soriano G, Rufer M, Delsignore A, Weidt S. Factors associated with non-treatment or delayed treatment seeking in OCD sufferers: a review of the literature. Psychiatry Res. 2014;220(1-2):1-10.

23. Besiroglu L, AS CI, Askin R. The predictors of health care seeking behavior in obsessive-compulsive disorder. Compr Psychiatry. 2004; 45(2):99-108.

24. Cullen B, Samuels JF, Pinto A, et al. Demographic and clinical characteristics associated with treatment status in family members with obsessivecompulsive disorder. Depress Anxiety. 2008;25(3):218-224.

25. Goodwin R, Koenen KC, Hellman F, Guardino M, Struening E. Helpseeking and access to mental health treatment for obsessive-compulsive disorder. Acta Psychiatr Scand. 2002;106(2):143-149.

26. WHO. In: Organization WH, editor. The European Mental Health Action Plan. Geneva, Switzerland: WHO; 2013.

27. Wahle F, Kowatsch T, Fleisch E, Rufer M, Weidt S. Mobile sensing and support for people with depression: a pilot trial in the wild. JMIR Mhealth Uhealth. 2016;4(3):e111.

28. APA. Diagnostic and Statistical Manual of Mental Disorders. IV-TR ed. Washington, DC: American Psychiatric Association; 2002.

29. Manzoni GM, Pagnini F, Castelnuovo G, Molinari E. Relaxation training for anxiety: a ten-years systematic review with meta-analysis. $B M C$ Psychiatry. 2008;8:41.

30. Keuthen NJ, O'Sullivan RL, Ricciardi JN, et al. The Massachusetts general hospital (MGH) hairpulling scale: 1. development and factor analyses. Psychother Psychosom. 1995;64(3-4):141-145.

31. Bohne A. Trichotillomanie [Trichotillomania]. Göttingen: Hogrefe; 2009.

32. O'Sullivan RL, Keuthen NJ, Hayday CF, et al. The Massachusetts general hospital (MGH) hairpulling scale: 2. reliability and validity. Psychother Psychosom. 1995;64(3-4):146-148.

33. WHO. The World Health Organization quality of life assessment (WHOQOL): development and general psychometric properties. In: Group TW, editor. Social Science \& Medicine. 1998;46:1569-1585.

34. Angermeyer M, Kilian R, Matschinger H. WHOQOL-100 and WHOQOL-BREF. Göttingen: Hogrefe; 2000.

35. Klaghofer R, Brähler E. Konstruktion und teststatistische Prüfung einer Kurzform der SCL-90-R. Z Klin Psychol Psychiatr Psychother. 2001;49:115-124.

36. Derogatis L, Fitzpatrick M, Maruish M. The SCL-90-R, the Brief Symptom Inventory (BSI), and the BSI-18. The Use of Psychological Testing for Treatment Planning and Outcomes Assessment. Vol. 3. 3 ed. Mahwah, NJ: Lawrence Erlbaum Associates Publishers; 2004:1-41.

37. Sheehan DV, Lecrubier Y, Sheehan KH, et al. The Mini-International Neuropsychiatric Interview (M.I.N.I.): the development and validation of a structured diagnostic psychiatric interview for DSM-IV and ICD-10. J Clin Psychiatry. 1998;59(suppl 20):22-33. quiz 34-57.

38. Ackenheil M, Stotz G, Dietz-Bauer R, Vossen A. Mini International Neuropsychiatric Interview. München: Psychiatrische Universitätsklinik; 1999.

39. Hamilton M. A rating scale for depression. JNeurol Neurosurg Psychiatry. 1960;23:56-62.

40. Maier W, Philipp M, Gerken A. Dimensionen der Hamilton-Depressionsskala (HAMD). [Dimensions of the Hamilton Depression Scale. Factor analysis studies]. European Archives of Psychiatry and Clinical Neuroscience. 1985;234(6):417-422. German.

41. Cohen J, editor. Statistical Power Analysis for the Behavioral Sciences. Hillsdale, NJ: Erlbaum; 1988.

42. Stein DJ, Grant JE, Franklin ME, et al. Trichotillomania (hair pulling disorder), skin picking disorder, and stereotypic movement disorder: toward DSM-V. Depress Anxiety. 2010;27(6):611-626.

43. Christenson GA, MacKenzie TB, Mitchell JE. Adult men and women with trichotillomania. A comparison of male and female characteristics. Psychosomatics. 1994;35(2):142-149. 
44. Woods DW, Houghton DC. Diagnosis, evaluation, and management of trichotillomania. Psychiatr Clin North Am. 2014;37(3):301-317.

45. Demyttenaere K, Bruffaerts R, Posada-Villa J, et al. Prevalence, severity, and unmet need for treatment of mental disorders in the World Health Organization World Mental Health Surveys. JAMA. 2004;291(21):2581-2590.

46. Chong SA, Abdin E, Sherbourne C, et al. Treatment gap in common mental disorders: the Singapore perspective. Epidemiol Psychiatr Sci. 2012;21(2):195-202.

47. Delsignore A. Does prior psychotherapy experience affect the course of cognitive-behavioural group therapy for social anxiety disorder? Can J Psychiatry. 2008;53(8):509-516.

48. Zimmerman M, Mattia JI. Principal and additional DSM-IV disorders for which outpatients seek treatment. Psychiatr Serv. 2000; 51(10):1299-1304.

49. Acarturk C, de Graaf R, van Straten A, Have MT, Cuijpers P. Social phobia and number of social fears, and their association with comorbidity, health-related quality of life and help seeking: a populationbased study. Soc Psychiatry Psychiatr Epidemiol. 2008;43(4): 273-279.

50. Wancata J, Friedrich F. Depression: a diagnosis aptly used? Psychiatr Danub. 2011;23(4):406-411.
51. Clarke D, Cook K, Smith G, Piterman L. What do general practitioners think depression is? A taxonomy of distress and depression for general practice. Med J Aust. 2008;188(12 suppl):S110-S113.

52. Marcks BA, Wetterneck CT, Woods DW. Investigating healthcare providers' knowledge of trichotillomania and its treatment. Cogn Behav Ther. 2006;35(1):19-27.

53. Marazziti D, Consoli G, Picchetti M, Carlini M, Faravelli L. Cognitive impairment in major depression. Eur J Pharmacol. 2010;626(1): $83-86$.

54. Helmreich I, Wagner S, Mergl R, et al. Sensitivity to changes during antidepressant treatment: a comparison of unidimensional subscales of the Inventory of Depressive Symptomatology (IDS-C) and the Hamilton Depression Rating Scale (HAMD) in patients with mild major, minor or subsyndromal depression. Eur Arch Psychiatry Clin Neurosci. 2012; 262(4):291-304.

55. Mazzotti E, Barbaranelli C. Dropping out of psychiatric treatment: a methodological contribution. Acta Psychiatr Scand. 2012;126(6): 426-433.

56. Weidt S, Delsignore A. Internet und psychische Gesundheit. In: Rössler W, Kawohl W, editors. Soziale Psychiatrie. Das Handbuch für die psychosoziale Praxis. Vol. 2. 1st ed. Stuttgart: W. Kohlhammer GMBH; 2013:420-431.
Neuropsychiatric Disease and Treatment

\section{Publish your work in this journal}

Neuropsychiatric Disease and Treatment is an international, peerreviewed journal of clinical therapeutics and pharmacology focusing on concise rapid reporting of clinical or pre-clinical studies on a range of neuropsychiatric and neurological disorders. This journal is indexed on PubMed Central, the 'PsycINFO' database and CAS,

\section{Dovepress}

and is the official journal of The International Neuropsychiatric Association (INA). The manuscript management system is completely online and includes a very quick and fair peer-review system, which is all easy to use. Visit http://www.dovepress.com/testimonials.php to read real quotes from published authors. 